\title{
Patrimonio inmaterial: tres estudios de caso en Ecuador, Colombia y Perú
}

\author{
Stephany Susana Torres Dávila* \\ Laura Falceri*
}

\section{RESUMEN}

En la actualidad, la noción de Patrimonio CUltural Se ha CONVERTido EN UNa especie de LUGaR COMÚn, No SÓlO PARA LAS CIENCIAS SOCIALES SINO TAMBIÉN PARA LA SOCIEDAD EN GENERAL. ESTE ARTÍCULO PRETENDE LOGRAR UNA MEJOR COMPRENSIÓN DE CÓMO SE PIENSAN Y SE VIVEN LAS NOMINACIONES PATRIMONIALES EN EL ÁMBITO DE LO "INMATERIAL", DESDE LA INSTITUCIONALIDAD, PERO TAMBIÉN DESDE LOS ACTORES GENERADORES DE LAS EXPRESIONES SOCIALES QUE HOY FORMAN PARTE DE LA “LISTA REPRESENTATIVA DE PATRIMONIO INMATERIAL DE LA HUMANIDAD" DE LA UNESCO. EN UN PRIMER MOMENTO SE REALIZARÁ UN ACERCAMIENTO A LAS NOCIONES Y CONCEPTOS RELACIONADOS CON LA PATRIMONIALIZACIÓN, PARA LUEgo PASAR A UNA EVALUACIÓN CRÍTICA DE ESTOS ELEMENTOS EN EL CONTEXTO PARTICULAR DE LA PATRIMONIALIZACIÓN DE LO INMATERIAL PROPUESTA POR LA UNESCO. UN SEGUNDO MOMENTO ENFOCAMOS LA MIRADA CRÍTICA EN LOS ACTORES SOCIALES Y LAS IMPLICACIONES QUE GENERAN LAS NOMINACIONES EN realidades particulares mediante el aCercamiento a tres casos de estudio en Colombia, Ecuador y Perú.

Palabras Claves: Patrimonio inmaterial - Zapara - Palenque San Basilio - Señor del Quyllur Ritti - UNeSCO.

\section{Abstract}

TODAY, THE NOTION OF CULTURAL HERITAGE HAS BECOME A SORT OF PUBLIC COMMONS, NOT ONLY IN THE ACADEMIC SPHERE, BUT ALSO FOR THE SOCIETY. THIS ARTICLE AIMS TO ACHIEVE A BETTER UNDERSTANDING OF HOW PATRIMONIAL HERITAGE IS UNDERSTOOD BY INSTITUTIONS, BUT ALSO HOW SOCIAL ACTORS, SPECIFICALLY THE CREATORS OF SOCIAL EXPRESSIONS THAT ARE NOW PART OF THE "REPRESENTATIVE LIST OF INTANGIBLE HERITAGE OF HUMANITY" BY UNESCO, UNDERSTAND AND APPROPRIATE THE CONCEPT. WE INCLUDE A THEORETICAL APPROACH TO THE IDEAS AND CONCEPTS RELATED TO PATRIMONIAL HERITAGE AND THE IMMATERIAL HERITAGE NOMINATIONS PROPOSED BY UNESCO AND EXPLORE THE SOCIAL, POLITICAL AND ECONOMIC IMPLICATIONS GENERATED BY THE NOMINATIONS. LATER, WE ATTEMPT A BETTER UNDERSTANDING OF HOW SOCIAL ACTORS RELATE TO NOMINATION THROUGH THE STUDY OF THREE cases in Colombia, Ecuador and Peru.

Keywords: Intangible heritage - Zapara - Palenque San Basilio - Señor del Quyllur Ritti - UNeSCO.

* Máster en Historia y Antropología de América - Universidad Complutense de Madrid; Diplomado en Gestión cultural - Facultad Latinoamericana de Ciencias Sociales, Licenciatura en Antropología Aplicada -Universidad Politécnica Salesiana. Antropóloga. SENPLADES - Secretaría Nacional de Planificación y Desarrollo. Correo electrónico: stephany.torres.d@gmail.com.

** PhD en Ciencias y tecnologías para la arqueología y los bienes culturales - Universidad de Ferrara, Italia; Maestría en Arqueología, Universidad de Pisa, Italia. Docente en la Carrera de Antropología Aplicada, Universidad Politécnica Salesiana. Correo electrónico: 1falceri@ups.edu.ec. 


\section{Introducción}

T a noción de patrimonio cultural se inscribe en el marco histórico de la modernidad ${ }^{1}$, particularmente en la modernidad tardía ligada a la globalización ${ }^{2}$ como tendencia socioeconómica, caracterizada por el aumento de la capacidad de interconexión a nivel global y la consecuente propensión a la homogenización cultural. A partir de la Segunda Guerra Mundial, los países consideraron necesario aunar esfuerzos para la conservación del patrimonio. Nace entonces la UNESCO, Organización de las Naciones Unidas para la Educación la Ciencia y la Cultura, fundada en 1945 y promueve los primeros lineamientos para el cuidado y la preservación del patrimonio material a través de la Convención para la Protección del Patrimonio Mundial Cultural y Natural, realizada en París en el año $1972^{3}$.

Se posiciona la propuesta de salvaguarda a partir de la crítica que se hace a la poca capacidad de protección, por parte de los Estados, del patrimonio material que había sufrido grandes percances durante la Segunda Guerra Mundial. Esta circunstancia legitima la intervención de la UNESCO como el ente transnacional que tendrá a su cargo, según su primera declaración, ayudar a la conservación, al progreso y a la difusión del saber (UNESCO, 1945). Estas nociones originadas en relación con la conservación del patrimonio material, se trasladan, con mínimas modificaciones, al ámbito del patrimonio inmaterial y se recogen en la Convención para la Salvaguarda del Patrimonio Inmaterial que tiene lugar en París en el año 2003. La Convención dispone la creación de la lista representativa de patrimonio inmaterial de la humanidad ${ }^{4}$, la lista de patrimonio inmaterial que requiere medidas urgentes de salvaguardia ${ }^{5}$, así como una lista de prácticas ejemplares ${ }^{6}$.

El presente artículo se plantea un análisis de las implicaciones, en el ámbito político, social y económico, de trasladar las nociones primigenias de lo material a los procesos de patrimonialización en el ámbito de lo inmaterial. Un segundo objetivo es acercar el lente a los actores sociales, evaluando la patrimonialización, no solamente desde lo institucional, sino desde la perspectiva del consumo cultural (Canclini, 1999). Se propone pensar sobre la sociedad que se construye y las formas de participación en esta construcción de sentido, a través de la investigación bibliográfica y estudios de caso. A partir de la lista representativa del patrimonio inmaterial de la UNESCO se seleccionaron tres casos de entre las nominaciones realizadas para Ecuador, Colombia y Perú. Mediante el análisis de los contextos socioeconómico, cultural, geográfico y temporal, se observa críticamente las contradicciones y paradojas propias de los procesos de patrimonialización concebidos dentro del marco de un estado-nación. Se pretende poner

1 La modernidad es un término que abarca un extenso lapso de tiempo, probablemente más de 500 años, lo que puede dificultar la posibilidad de situar su temporalidad. Mignolo propone una lectura que divide este extenso periodo en cuatro etapas; "la primera es la cara ibérica y católica, con España y Portugal a la cabeza (1500-1750, aproximadamente); la segunda es la cara del «corazón de Europa» (Hegel), encabezada por Inglaterra, Francia y Alemania (1750- 1945), y, por último, está la cara estadounidense liderada por Estados Unidos (1945-2000). Desde entonces, empezó a desarrollarse un nuevo orden global: un mundo policéntrico interconectado por el mismo tipo de economía" (Mignolo, 2003: 41-42). El presente estudio se encuadra en la última etapa. Es importante considerar que la UNESCO se funda en 1945, después de la Segunda Guerra Mundial.

2 Beck (2008) caracteriza a la globalización como una importante transformación cultural, la paulatina universalización de los modos de vida, símbolos culturales y modos de conducta transnacionales, pero también ligada a procesos particulares (locales), con lo cual, no sólo implica una des-localización sino también un re-localización, mediante el diálogo y el conflicto translocal.

3 En referencia a los monumentos, los conjuntos arquitectónicos, los lugares arqueológicos y las reservas naturales que son considerados icónicos para un determinado Estado desde la óptica institucional de la UNESCO.

4 La lista representativa de patrimonio inmaterial de la humanidad nace en el año 2001 con el nombre de Obras Maestras del Patrimonio Oral e Inmaterial de la Humanidad. En el año 2005 ya suman 90 Obras Maestras que serían traspasadas a la mencionada lista representativa, creada mediante la Convención para la Salvaguarda del Patrimonio Inmaterial del año 2003, y que entraría en vigor en el 2006. El cambio de denominación no es fortuito, pues se intentó ampliar la noción de exclusividad de Obra Maestra a una perspectiva más general de representatividad.

5 Lista de riesgo en donde se inscriben ciertas expresiones que parecen estar en peligro de desaparición y que la UNESCO considera deberían ser preservadas.

6 Programas, proyectos o actividades que, según la UNESCO, reflejan, del modo más adecuado los principios y objetivos de la Convención. Estos proyectos son tomados como ejemplos a seguir. 
en evidencia la importancia de la mirada antropológica en los procesos de patrimonialización, dado que ésta permite observar, entender y comunicar los efectos concretos que generan estas nominaciones en la vida de los actores sociales. Este aspecto parece haber sido olvidado, o cuando menos, relegado por las instituciones que trabajan en la gestión cultural y, de cierta manera, también en el ámbito académico.

\section{El patrimonio inmaterial}

Para la UNESCO (2003), el Patrimonio Cultural Inmaterial son "[...] los usos, representaciones, expresiones, conocimientos y técnicas -junto con los instrumentos, objetos, artefactos y espacios culturales que les son inherentes- que las comunidades, los grupos y en algunos casos los individuos reconozcan como parte integrante de su patrimonio cultural". Partiendo de esta conceptualización surge la pregunta ¿Por qué, siendo la cultura algo tan propio de sus actores, ésta debe considerarse patrimonio de una nación o de toda la humanidad? La noción de patrimonio, contextualizada en los tiempos de creación y consolidación de los estados-nación, se fue construyendo en base a un sentido de lo nacional y de la propiedad. Se trata entonces de una construcción social moderna, que no es universal, pues no se produce en todas las sociedades, ni en todas las épocas. Es más bien "un artificio ideado por alguien, en algún contexto particular y para fines particulares, y es susceptible de cambio en base a nuevos criterios o intereses" (Llorenç, 1997: 20).

Frente a ello, el presente artículo presenta una revisión crítica de las implicaciones de las nominaciones de "patrimonio inmaterial de la humanidad" generadas por la UNESCO, en la línea de Stuart Hall (2005), quien propone pensar el patrimonio como una práctica discursiva, según la cual la nación construye para sí misma una especie de memoria social colectiva, caracterizada por ser altamente selectiva, que resalta y privilegia determinados principios, medios y fines a la vez que recorta, silencia, desautoriza y olvida narrativas diferentes. Esto, con la intención de representar simbólicamente una identidad nacional, y de conservar y exponer diversos referentes simbólicos, los cuales adquieren un carácter sacralizado, esencial e inmutable.

\section{Una mirada política de las nominaciones patrimoniales}

El Estado y los organismos internacionales adquieren una especie de posesión sobre las expresiones culturales cuando estas son patrimonializadas. Este es un ejercicio de poder mediante el cual las naciones se apropian de las prácticas culturales. Villaseñor \& Zolla (2012) advierten que este modo de proceder constituye una trasgresión en contra de los derechos culturales de los grupos sociales, puesto que se abre la posibilidad a una importante injerencia de las políticas nacionales en relación con la expresión patrimonializada. El mismo término patrimonio lleva implícita una noción de propiedad, lo que resulta peligroso si recordamos que el patrimonio inmaterial incluye todo aquello que podemos entender como cultura, que es la vida misma y las posibilidades de reproducción de la diversidad cultural. La patrimonialización de estas experiencias sociales implica el riesgo de que se genere una especie de usurpación simbólica ${ }^{7}$ desde los grupos hegemónicos que buscan integrar la diferencia, de manera simplificada y descontextualizada, a través de las industrias culturales $^{8}$, que se han consolidado como uno de los medios más efectivos para construir ciudadanía.

7 "Un recurso que el poder ha instrumentalizado es usurpar aquellos símbolos que sabiéndolos ajenos, tienen una profunda eficacia en la construcción de sentido; símbolos que pueden ayudar a construir un ordenamiento de la sociedad que posibilite la preservación del orden dominante. A este proceso lo hemos caracterizado como usurpación simbólica" (Guerrero, 2004: 43).

8 Las industrias culturales incluyen cine, televisión, video, medios masivos, que, según explica Canclini (1999: 90), son hoy "el principal recurso para fomentar el conocimiento recíproco y la cohesión entre los múltiples organismos y grupos en que se fragmentan las grandes ciudades". Es por medio de los mensajes que trasmiten estos medios que se van formando las nociones de ciudad y ciudadano. 
En cuanto a la selección de los elementos que llegan a formar parte de la lista representativa, llevado a cabo por el Comité de la UNESCO, no existe claridad sobre los parámetros que se utilizan en el proceso. Este vacío informativo genera uno de los mayores interrogantes. Velasco (2012) propone que es posible que el reconocimiento que promueve UNESCO responda, en buena medida, a ciertos acuerdos políticos y no tanto a criterios técnicos. La selección también tiene la limitante de encontrarse basada en una matriz de pensamiento occidental, con un fuerte tinte etnocéntrico, que asume que la conservación del patrimonio cultural inmaterial de la humanidad es un valor universal.

En este sentido, Gomez Rendón (2014) propone una clasificación del patrimonio como propiedad y como apropiación. En el primer caso se habla de una herencia, trasmitida de manera intergeneracional tanto de bienes como de manifestaciones, mientras en el segundo caso es el resultado de un proceso de adquisición de los mismos que se reclaman propios por medio de otros canales que no son los de la herencia. La patrimonialización de lo cultural involucra los dos procesos, por un lado, la apropiación del patrimonio con un alto grado de institucionalización, cada expresión cultural debe pasar por una serie de filtros (ONG's, institutos de patrimonio, ministerios de cultura, otros organismos nacionales e internacionales) con la finalidad de legitimar su nominación patrimonial ${ }^{9}$. Por el otro lado los actores sociales generan procesos de apropiación ya que son los creadores de la expresión tienen capacidad de acción y elección. Como explica Ariño (2009), "el patrimonio no se define ya única y principalmente desde arriba, ni exclusivamente desde los expertos, sino mediante cooperación y negociación entre una pluralidad de actores". Las nominaciones patrimoniales pueden ser estratégicamente utilizadas por el subalterno, incluso como resistencia, por lo que bien se podría hablar de una heterogeneidad de relaciones políticas con el patrimonio.

\section{¿Y los actores sociales?}

Las expresiones inmateriales están en constante interacción con los actores sociales, están vivas, son cambiantes, están cargadas de simbolismo y emoción, por tanto presentan mutaciones, conflictos de intereses, crisis y renovaciones. Varios autores, entre ellos Chaves et al. (2010), Ariño (2009), Villaseñor y Zolla (2012), Estraffi, (2014) y Rendón (2014) advierten que la patrimonialización intenta negar y ocultar este fenómeno y observa las expresiones culturales como un objeto esencializado y paralizado en el tiempo y el espacio. Este fenómeno se hace evidente en uno de los fundamentos del proceso de patrimonialización: la noción de salvaguardia ${ }^{10}$, que promueve la participación de instituciones exógenas en la gestión del patrimonio, dejando en segundo plano los procesos internos, los conflictos, las opciones de los actores y su construcción histórica.

La declaratoria patrimonial tiende a proteger la parte visible de una práctica y no su lógica social. Se esencializa la práctica cultural porque se espera que la expresión se mantenga auténtica a los ojos occidentales, lo que implica un rechazo a ciertas modificaciones en las formas expresivas, probablemente debido a la dificultad de entender lo cultural en toda su complejidad. Otro fenómeno recurrente en los procesos de patrimonialización es la folcklorización. Santoyo (2006) explica que la forma toma supremacía sobre su parte simbólica, con lo cual, la formación

9 Esta intervención institucional es promovida desde la UNESCO, que, en la Convención para la Salvaguardia del Patrimonio Cultural lnmaterial del 2003, solicita a los Estados miembros realizar inventarios locales, crear programas de planificación y organismos competentes, fomentar estudios e investigaciones y adoptar medidas de orden jurídico, técnico, administrativo y financiero.

10 Salvaguardia entendida, según la Convención para la Salvaguardia del Patrimonio Cultural Inmaterial del 2003, como "las medidas encaminadas a garantizar la viabilidad del patrimonio cultural inmaterial, comprendidas la identificación, documentación, investigación, preservación, protección, promoción, valorización, transmisión básicamente a través de la enseñanza formal y no formal- y revitalización de este patrimonio en sus distintos aspectos" (Artículo 2). 
de inventarios viene a ser una especie de certificación institucional del folclor. La activación patrimonial se convierte en un proceso de profanación de lo sagrado; las manifestaciones culturales se traducen en términos occidentales, y se ven obligadas a mantener una noción de autenticidad que parte de imaginarios sobre lo exótico. Se trata de un ejercicio de poder a través del Estado, ONG's, gestores sociales o los mismos investigadores y académicos que vigilan que la acción cultural sea coherente, estable y se encuentre dentro de parámetros que no cuestionen o alteren las estructuras actuales. Este tinte exotizante se confirma al observar que la mayor parte de las expresiones, en los países de estudio, están relacionadas con lo indígena, lo afro, lo popular y lo subalterno.

El último elemento a destacar es la jerarquización que las expresiones culturales van adquiriendo a partir de esta tendencia clasificatoria que coloca ciertas expresiones por sobre otras. Autores como Canclini, (1999), Chaves et al. (2010) y Velasco (2012) denuncian que la selección de determinadas expresiones y la exclusión de otras sirve para la reproducción y la legitimación de cierto relato histórico nacional que deja "la otra" parte de la historia inadvertida y en el olvido. La jerarquización también se da a nivel interno de las expresiones culturales, cuando se opta por priorizar aspectos externos, visuales, auditivos y, en general, materiales, por encima de otros (Villaseñor \& Zolla, Del patrimonio cultural inmaterial o la patrimonialización de la cultura, 2012).

\section{Patrimonialización y mercantilización}

La mercantilización de la cultura, mediante la atracción del turismo y el consumo de bienes patrimoniales como forma de entretenimiento, es uno de los temas más sensibles. La apropiación, por parte de agentes externos, de una determinada expresión con la finalidad de venderla o comerciar con ella es posible porque actualmente no hay claridad en cuanto al derecho de uso, propiedad, circulación y distribución de los bienes y saberes patrimonializados. (Arocha, 2007 en Chaves et al, 2010: 13).

En este juego económico, los Estados también tienen un papel relevante, pues se han comprometido con la salvaguardia del patrimonio, pero a la vez se ven en la necesidad de potenciar el turismo en sus países, para lo cual se requiere transformar ciertos espacios culturales en espectáculos para la industria cultural (Castro, 2009 en: Chaves et al., 2010). De esta manera se va expropiando de sus prácticas a los portadores de la cultura para servir a un mercado cultural y se genera una paradoja compleja, en la cual el afán de salvaguardia de una expresión evita su desaparición, pero a su vez puede llegar a desvirtuarla y, en ocasiones, a despojarla de su fuerza vital con el fin de convertirla en un producto para las industrias culturales.

Existen una serie de matices relacionados con la mercantilización de la cultura, muchas veces ligados a las estrategias de supervivencia cultural. En varias ocasiones las declaratorias han abierto espacios de diálogo con el Estado, lo que a su vez ha permitido atender intereses locales. Asimismo, los actores sociales pueden optar por comercializar una determinada expresión sin que ello implique que la expresión entre en crisis o pierda su significado local. Los estudios de caso presentados más adelante ayudarán a explorar y comprender estas posibilidades.

\section{La patrimonialización, desde los actores}

En esta segunda parte del artículo se toman algunos casos concretos de expresiones culturales para analizar cuáles han sido las diversas formas de relacionamiento de los actores sociales con la patrimonialización de una representación inmaterial. A continuación un cuadro resumen de las prácticas culturales seleccionadas: 


\section{tabla 1. Prácticas culturales seleccionadas}

Datos Generales

\begin{tabular}{|l|c|c|c|c|c|c|}
\hline & $\begin{array}{c}\text { Nominaciones } \\
\text { Previas }\end{array}$ & $\begin{array}{c}\text { Fecha de } \\
\text { nominación }\end{array}$ & Habitantes & $\begin{array}{c}\text { Reconocimiento } \\
\text { constitucional }\end{array}$ & Periodicidad & Ubicación \\
\hline Zápara & No & 2001 & $200 / 300 / 500$ & $\begin{array}{c}\text { Plurinacional- } \\
\text { intercultural }\end{array}$ & Diaria & aislado \\
\hline Palenque & Sí & 2005 & 3500 & Multicultural & Diaria & $\begin{array}{c}\text { cercano a las } \\
\text { urbes }\end{array}$ \\
\hline Qoyllurit'i & Sí & 2011 & $7000 / 8000$ & Multicultural & $\begin{array}{c}\text { una vez al año } \\
\text { - una semana }\end{array}$ & $\begin{array}{c}\text { cercano a las } \\
\text { urbes }\end{array}$ \\
\hline
\end{tabular}

Elaboración: Stephany Torres

La selección de los casos pretende abarcar la mayor diversidad posible. "El patrimonio oral y las manifestaciones culturales del pueblo zápara" se refiere a una nacionalidad indígena de la Amazonía ecuatoriana. Con "El espacio cultural de Palenque de San Basilio" se mira la vida de comunidades afrodescendientes en la costa colombiana. Finalmente, "la peregrinación al santuario del Señor de Qoyllurit'i”' en Perú se desarrolla en comunidades andinas.

\section{El patrimonio oral y las manifestaciones culturales del pueblo Zápara}

Sápara ${ }^{11}$ significa "gente de la selva" (Andrade, (2001). Kwatupama Sapara, Palabra Zápara, 2001), y en efecto, el territorio que ocupan se encuentra en una de las zonas más aisladas y de difícil acceso del Ecuador y está rodeado de una gran biodiversidad y de muchos recursos petroleros anhelados por las industrias. El número de la población es difícil de determinar, se calcula que serían "alrededor de 200 personas, aunque también se dice que son 300 zápara, hijos de padre y madre zápara y unas 1071 zápara mezclados con quichuas, shuar y shiwiar (Moya, 2007: 14$)^{12}$.

La lengua zápara pertenece a la familia lingüística zaparaona, en las comunidades Zápara su uso se combina con el kichwa y el castellano, por lo que su utilización ha ido disminuyendo con el tiempo. Según una nota del diario El Telégrafo (26 julio 2017), para el año 2017 solamente 4 personas, con edades entre los 80 y 95 años la manejan con fluidez. Según Manari Ushigua, presidente de la nacionalidad zápara, actualmente la lengua zapara se está perdiendo porque hay quienes prefieren hablar quichua antes que el idioma zápara. Frente a esta realidad la nacionalidad zápara ha emprendido algunos esfuerzos, han implementado sus propias escuelas. También se han fortalecido algunas prácticas oníricas, las cuales permitían generar una cierta continuidad del pasado en el presente, en base a encontrar y recrear un vínculo con los ancestros a través del sueño (Bilhaut, El sueño de los Zaparas: Patrimonio onírico de un pueblo de la alta Amazonia., 2011).

11 Sasiko, una mujer sápara explica que "záparo (sáparo) es el nombre que dan a las canastas en su lengua, pero también asegura que sápara era el apellido de todos ellos, antes de que la religión y el Estado les obligue a cambiar sus nombres" (Andrade: 2001: 13).

12 La dificultad para calcular el número exacto se genera a partir de la práctica de los matrimonios interétnicos y a los múltiples conflictos que los zápara han tenido que enfrentar en su historia y que los ha obligado a dispersarse o a adherirse a otros pueblos indígenas. 


\section{¿Una sola nacionalidad zápara?}

Es importante aclarar que la nacionalidad zápara no es homogénea; su división principal se registra en el tiempo de explotación del caucho ${ }^{13}$. Los zápara del Curaray, al ser acechados por los achuar, optaron por una estrategia de integración y fueron virtualmente absorbidos por los kichwas de Canelos. En cambio, los zápara del Conambo, que aparentemente habían sido exterminados por los kichwas, fueron adoptando el kichwa como lengua materna, pero mantuvieron sus apellidos y su identidad étnica. (Reeve, 1987: 103 en Moya, 2007: 236-237).

Este segundo grupo (en adelante llamado zápara autónomo) es el que habría recibido la nominación de la UNESCO. Existe también otro grupo zápara que, en los años cuarenta, cuando tuvo lugar la guerra entre Ecuador y Perú, fue desplazado al Perú. Andrade (2001: 12) explica que "existen alrededor de 200 záparas dispersos dentro de comunidades habitadas por otros grupos humanos mayoritarios, quechuas y mestizos fundamentalmente". Al respecto, Bilhaut (2011: 52), se pregunta si es pertinente hablar de záparas en el Perú, "puesto que ellos mismos continúan auto-designándose como alamas o kichwas del Tigre". La nominación de la UNESCO incluye a los zápara autónomos y aquellos que viven en el Perú. La facción perteneciente al lado ecuatoriano es la que se ha vinculado a las negociaciones relacionadas con la patrimonalización con diversos organismos, incluyendo el Estado y la UNESCO. Este contexto ha derivado en que la declaratoria de "patrimonio inmaterial" sea fuente de conflictos entre los zápara autónomos y los zápara evangélicos, como también con la nacionalidad achuar, todos interesados en acceder a los beneficios de la declaración de la UNESCO. Es destacable la poca participación de los zápara de Perú en el proceso, aunque estos sí están reconocidos por la nominación de la UNESCO.

\section{Cultura zápara, patrimonio inmaterial de la humanidad}

Hay pocos registros de la historia del pueblo zápara, y los que existen dan cuenta de los fuertes procesos de violencia real y simbólica que han vivido. Un texto publicado en Ecuador en 1992 los declara "oficialmente desaparecidos" (Barriga, 1992: 264 en: Andrade, 2001: 13). A pesar de todo esto, y de la casi extinción de la lengua zápara, su cultura ha permanecido en el tiempo, tanto así que Moya (2007) considera que los zápara autónomos del Conambo se han mostrado "impenetrables", lo que les ha permitido conservar su autonomía y preservar su identidad. En el año 2001 el patrimonio oral y las manifestaciones culturales del pueblo Zápara pasan a formar parte de las Obras Maestras de la Humanidad ${ }^{14}$. Márquez (2003) explica que en un primer momento el proceso de patrimonialización no fue guiado por el pueblo zápara sino por otras instituciones, como la Casa de la Cultura Ecuatoriana, quienes llevaron a cabo el proceso con una muy escasa participación de los zápara. El pueblo zápara tuvo conocimiento de su nuevo estatus como "patrimonio de la humanidad" después de haber sido seleccionado, lo que pone en evidencia aquella crítica esbozada en líneas anteriores sobre cómo la institucionalidad atraviesa el proceso de aplicación y pasa por sobre los actores sociales. A pesar de ello, es interesante notar que los zápara se empoderaron rápidamente de las ventajas que la nominación les generaba, de tal modo que, desde organizaciones como la ANAZPPA ${ }^{15}$ (Asociación de la Nacionalidad

13 Las crisis más relevantes y que permanecen vivas en la memoria colectiva son: la extracción del caucho, desde mediados del XIX hasta principios del siglo XX; la invasión peruana en 1941; y la explotación petrolera que continúa hasta el presente. Andrade (2001: 20) explica que en el tiempo de explotación del caucho, que duraría alrededor de veinte años, llegaron muchos colonos mestizos y, con ellos, exigencias y maltratos que casi llevan a la desaparición a varios pueblos, entre ellos los záparas, que se vieron reducidos hasta su casi total desaparición.

14 En el 2001 se da el reconocimiento como Obra Maestra. Posteriormente, según consta en los documentos de la tercera sesión del comité intergubernamental realizado en Estambul entre el 4 y 8 de noviembre del 2008, esta expresión pasa a formar parte de la lista representativa.

15 Formada en 1998 por un grupo de 115 záparas del Conambo como parte de los esfuerzos para iniciar un proceso de revitalización de su idioma y costumbres (Andrade, 2001). 
Zápara de la Provincia del Pastaza) y posteriormente desde la ONZAE ON $^{16}$ (Organización de la Nacionalidad Zápara del Ecuador), aprovecharon la vinculación con la UNESCO y la resonancia que tiene el ser considerado patrimonio de la humanidad para acceder a beneficios ofrecidos por ONG's y para que su voz tenga mayor peso en foros regionales y nacionales. Estos nuevos espacios y vínculos representan una importante presión externa, por lo que Moya (2007) advierte que existen nuevas amenazas que tienen que ver con el manejo de su territorio ancestral por parte de agentes externos; la introducción de formas organizativas extrañas a su cultura, como la castellanización; la inserción en la educación formal en el caso de los jóvenes; y la inserción de los líderes comunitarios en nuevos roles ligados a la burocracia. Además explica que estos procesos de integración tienen consecuencias sobre el sistema económico y productivo ya que se han generado nuevos ingresos monetarios que antes no existían en las comunidades y que de manera general no resultaban necesarios, pues se manejaba una economía autárquica ${ }^{17}$.

En cuanto a los aspectos positivos relacionados con el respaldo internacional y nacional que han logrado obtener los zápara a partir de este reconocimiento, Bartolo Ushigua, líder comunitario, explica que se han podido llevar a cabo acciones como la redefinición territorial y programas encaminados al fortalecimiento de la lengua y la cultura zápara. También ha motivado el trabajo por la recuperación de su cultura y sus derechos en la sociedad (Entrevista realizada a Bartolo Ushigua, 2003 citado en Márquez, 2003: 68).

Se hace evidente que la patrimonialización ha generado una posibilidad de negociación y resistencia frente al Estado, petroleras y ONG's, pero que a su vez fuerza a varios miembros a dejar su vida comunitaria para interactuar con estas instituciones, que, en algunos casos, de manera sigilosa, se involucran en su cotidianeidad para lograr agendas propias.

\section{El espacio cultural de Palenque de San Basilio}

Palenque es un poblado de 3.500 habitantes, ubicado en el departamento de Bolívar, muy cercano a la ciudad de Cartagena de Indias, en Colombia. Fue fundado en tiempos de la colonia por personas procedentes de África que escapaban de la esclavitud. La particularidad de Palenque de San Basilio radica en haber sido reconocido por parte de las autoridades españolas como el primer palenque libre y en ser el único que persiste en el tiempo, con lo cual su cultura se ha nutrido de diversas fuentes y es, hoy en día, testimonio de supervivencia, adaptación y lucha. (Presidencia de la República de Colombia, Ministerio de Cultura, Instituto Colombiano de Antropología e Historia, 2002 ${ }^{18}$. Desde una perspectiva histórica, hasta la década de los ochenta prevalecía una abierta discriminación racial, cultural y lingüística por parte de la sociedad blanco-mestiza colombiana, originada en la concepción eurocéntrica y occidentalizada de nación y ciudadano. Esta percepción de la cultura palenquera cambia en base a dos procesos casi simultáneos: la revalorización y revitalización cultural generada desde los propios habitantes de Palenque; y el reconocimiento de la diversidad étnica y cultural de Colombia desde un ámbito institucional, esto es, en las declaratorias patrimoniales y en la Constitución Política de 1991 (Rendón, Bonga, el caso de la activación patrimonial de San Basilio de Palenque y el desplazamiento forzado de sus campesinos a causa del terror en Montes de María, 2014).

16 La ONZAE (Organización de la Nacionalidad Zápara del Ecuador) no es la única organización de los záparas, ya que está también la ONAZE (Organización de la Nacionalidad Zapara Evangélica). Estas organizaciones mantienen relaciones conflictivas y la nominación patrimonial solamente se refiere al grupo zápara representado por la primera.

17 Moya (2007) advierte que existen presiones para que se inicie un proceso de monetización en la economía zápara, y los líderes cada vez se sienten más comprometidos con estos proyectos, que de ser aceptados, alterarían completamente la realidad de las comunidades.

18 Palenque de San Basilio no fue el primero en establecerse en América, ya que a finales del siglo XVI existía también el mítico quilombo de Palmares en territorios de la colonia portuguesa. Sin embargo, este fue destruido después de cien años de resistencia, mientras Palenque sobrevive hasta hoy (Presidencia de la República de Colombia, Ministerio de Cultura, Instituto Colombiano de Antropología e Historia, 2002). 


\section{Palenque y su anexión a las "Obras maestras"}

Muchos de los cambios ocurridos en Palenque en las últimas décadas se deben a procesos de migración, pero destaca lo ocurrido en los años ochenta, tiempo en que los migrantes retornaron a su tierra, formados, en su mayoría, como maestros y con la clara intención de iniciar un proceso de revitalización de su cultura. Salge (2012: 234) explica que "desde una opción interna se decidió dar un nuevo valor a la lengua, las narraciones orales, a la figura mítica de Benkos Bioho como héroe fundacional de Palenque y a la búsqueda de rasgos africanos en sus manifestaciones culturales". Este empoderamiento de la identidad étnica negra permitió a los palenqueros llegar a ser seleccionados por el Comité de Patrimonio colombiano para participar en el programa de proclamaciones de la UNESCO y posteriormente ser declarados Obra Maestra del Patrimonio Oral e Inmaterial de la Humanidad. Para justificar la inscripción de Palenque de San Basilio, el Estado colombiano, mediante su Ministerio de Cultura y el Instituto Colombiano de Antropología e Historia, en asociación con las organizaciones de Palenque, generaron un expediente de candidatura, en el cual proponen que su valor excepcional radica en los siguientes puntos:

- Palenque, primer pueblo libre de América: Benkos Bioho sería el héroe fundador de Palenque. A finales del siglo XVI organizaría la resistencia y a la vez la negociación con la administración colonial.

- Lengua palenquera: única lengua en el mundo que se clasifica como un criollo de base léxica española y con características morfosintácticas de lenguas autóctonas del continente africano.

- Los Kuagro: grupos de edad únicos en la diáspora afroamericana en Colombia. La pertenencia al grupo se define por un rango de edad y por lo general en un territorio determinado" (Restrepo \& Pérez, San Basilio de Palenque: Caracterizaciones y riesgos del Patrimonio intangible, 2005).

- Lumbalú ${ }^{19}$ y la medicina tradicional: el lumbalú constituye una serie de rituales fúnebres específicamente del territorio Bantú; une el baile, el canto y la danza como muestra de melancolía, recuerdos o reflexión. Este rito se lleva a cabo cuando fallece una persona y tiene una duración de nueve días y nueve noches Por otro lado, la medicina tradicional, contiene un cúmulo de saberes ancestrales que conjugan los conocimientos africanos, hispánicos e indígenas para el tratamiento de las enfermedades (Ibíd.: 63).

- Expresiones musicales e identidad palenquera: existen dos corrientes musicales, la primera, más tradicional, compuesta por géneros como el bullerengue sentado, son palenquero y lumbalú, con instrumentos también tradicionales como la marimbula y un complejo de tambores. Y la segunda corriente, más moderna, se expresa en la champeta criolla (Ibíd.: 65).

A pesar de la importante iniciativa local en cuanto al proceso de revitalización cultural, en lo relacionado con la candidatura a obra maestra, pocas personas participaron y algunas no tuvieron conocimiento alguno del proceso ${ }^{20}$.

19 Rendón (2014) explica que en San Basilio de Palenque el ritual fúnebre lumbalú es tan sagrado que algunas personas se mostraban reticentes a aceptar que fuera denominado patrimonio.

20 El Observatorio de patrimonio material, inmaterial y arqueológico de Colombia (2009) realizó una pequeña encuesta con la intención de recoger las percepciones sobre el proceso de declaratoria en Palenque de San Basilio. En ella se destaca que el $40 \%$ de la población encuestada desconocía el proceso y sólo el 15\% de la muestra participó de alguna manera en el mismo. La encuesta fue realizada a 215 personas, un número reducido si consideramos que Palenque tiene alrededor de 3.500 habitantes, es decir, un 6,14 \% de la población. 


\section{Palenque, modernidad y turismo}

Colombia, al igual que otros países latinoamericanos, se ha adherido al discurso de un multiculturalismo liberal con el eslogan de "nación incluyente y multicultural". El estatus de patrimonio es viable en tanto y en cuanto pueda mantener la representación esperada en el discurso político. Así, los sujetos de las prácticas pasan de ser agentes creadores a ser objetos de la representación nacional. Palenque se entiende como un lugar mítico, de otro tiempo, que ha sido domesticado para poder representar el proyecto multicultural nacional colombiano. Esto muestra que la patrimonialización puede no ser efectiva en la generación de inclusión, en este caso genera incluso un sesgo social discriminatorio, en particular con relación a lo afro, generando una especie de racismo y exotización de lo negro. A pesar de ello, no se puede desmerecer el hecho de que la nominación ha abierto posibilidades para que los representantes del Palenque logren sostener algún proceso de diálogo y/o negociación con el poder del Estado, aunque de manera limitada.

Otra arista importante en esta historia es el incremento del turismo a partir de la declaratoria. En consecuencia, las comunidades palenqueras dejan de lado ciertas prácticas económicas como la agricultura, para enfocarse en el turismo cultural que, en general, deja poco dinero en las comunidades y la mayor parte en los bolsillos de las agencias de turismo. También preocupa que el tipo de turismo que se practica se enmarca en una tendencia folcklorizante, según la cual se espera que una localidad se muestre al turista, no necesariamente como es sino como se espera que $\operatorname{sea}^{21}$. El contexto de reproducción social de los palenqueros es aún más complejo si se toma en cuenta los problemas propios de la modernidad, como la migración forzada, la situación de crisis económica, el ingreso de nuevas tecnologías, la discriminación racial, la aculturación y la falta de planes de transmisión cultural. La presente generación de abuelos y abuelas no logran pasar a las nuevas generaciones sus conocimientos y habilidades en los diferentes aspectos de la tradición cultural palenquera. La brecha generacional es hoy mayor que en cualquier época anterior (Rendón, 2014).

En Palenque se observa procesos simultáneos de resistencia y negociación con el poder; también se hace evidente la penetración de prácticas culturales homogeneizantes en unos casos, y folcklorizantes en otros. Al interior de Palenque se pueden encontrar posiciones divergentes, existiendo algunos grupos con mayor interés en la integración a la nación a nivel social y cultural, y otros que ven en la revitalización de su cultura histórica la clave para enfrentar los tiempos modernos.

\section{La peregrinación al santuario del Señor de Qoyllurit’i}

Qoyllurit'i traducido del quechua significa "Estrella de la Nieve", nombre con el cual se conoce al santuario religioso al que, una vez al año, peregrinan decenas de miles de fieles. El grueso de los peregrinos son campesinos indígenas que vienen desde Cuzco, Lima y otras ciudades andinas. Se rinde culto a la imagen de un Cristo, pintada en una roca sagrada, ubicada dentro del santuario al pie de los glaciares del nevado Colque Punku, junto al nevado Ausangate, en la cordillera de Vilcanota, al Sur de Perú. El punto de partida de la procesión está a 4.050 m.s.n.m.; el último punto de la peregrinación se ubica entre los 4850 m.s.n.m. (Ceruti, Qoyllur Riti: etnografía de un peregrinaje ritual de raíz incaica por las altas montañas del Sur de Perú, 2007). La festividad inicia el fin de semana que precede a la celebración cristiana del Corpus $\mathrm{Cristi}^{22}$. Tiene tres días centrales, aunque las actividades rituales en su totalidad duran alrededor

21 Llorenç Prats habla de una "espectacularizacion de la realidad" ya que, frente a una masificación del turismo los protagonistas de las prácticas se ven obligados a responder a imagines estereotipadas (1997).

22 La Celebración del Corpus Cristi es variable, se lleva a cabo 60 días después del Domingo de Pascua; formalmente es el jueves que sigue al noveno domingo siguiente a la primera luna llena de primavera. 
de una semana ${ }^{23}$. La peregrinación acoge tanto a personas que participan completamente en el ritual como a personas que se integran en calidad de observadores o participan de manera parcial. En este último grupo encontramos a fieles, turistas extranjeros, periodistas, fotógrafos y antropólogos (Carreño, 2012). Se trata de una de las peregrinaciones de mayor dimensión en el mundo andino, pues congrega una serie de tradiciones de origen inca ${ }^{24} \mathrm{y}$ de fuentes modernas como el catolicismo y otras absolutamente contemporáneas agrupadas bajo la nominación new age.

Hay también nuevas influencias, propias de los tiempos globales; los peregrinos ya no proceden solamente de grupos campesinos o mestizos de los pueblos cercanos al santuario, como era común hace pocos años, sino que hay nuevos devotos, procedentes de ámbitos urbanos nacionales e internacionales. Asimismo, las celebraciones del taytacha Qoyllurit'i se han trasladado a localizaciones geográficas tan lejanas como Lima o Nueva York, mostrando que las identidades son móviles y que, en los tiempos modernos, la globalización ha permitido y promovido la aparición de comunidades transnacionales en nombre del Señor del Qoyllurit' $i^{25}$. Las identidades posmodernas son transterritoriales y multilingüísticas y se estructuran desde de los mercados; en un marco postmoderno superan las fronteras de los países (Canclini N. G., 1999).

\section{Eı Señor del Qoyllurit’i y su patrimonialización}

La declaración del Santuario del Qoyllurit'i y de la festividad como herencia cultural de la nación peruana se dio en el año 2004 a través del Instituto Nacional de Cultura del Perú. La iniciativa para aplicar a obra maestra de patrimonio oral e inmaterial de la humanidad surge desde la Hermandad del Señor del Qoyllurit'i y el Concejo de Naciones Peregrinas, con apoyo de instituciones gubernamentales como el Instituto Nacional de Cultura. En el 2011 la peregrinación llega a ser reconocida como "Patrimonio inmaterial de la humanidad". La UNESCO resaltó el carácter participativo del proceso y lo consideró un ejemplo para expresiones que aspiren a formar parte de la lista (Bellido, Qoyllurit'i, una peregrinación que mueve montañas., 2012). Independientemente de la nominación patrimonial, el volumen y la popularidad de la fiesta han ido en franco aumento durante la última década. Si en los setenta había aproximadamente 10.000 peregrinos, para los noventa la cifra llegaba a los 60.000 (Ávila, 2004: 6) y en la actualidad se habla de aproximadamente 90.000 participantes. Con tal preámbulo, una de las principales preocupaciones es la necesidad de proteger el espacio natural en el que se desarrolla la procesión, tanto en el tema de manejo de desechos como en la concienciación de los asistentes en relación con el cuidado ecológico (UNESCO, Expediente de aplicación, La peregrinación al santuario del Señor de Qoyllurit'i, 2010). El peligro que afecta a la peregrinación no es su posible desaparición sino las consecuencias de un aumento vertiginoso de fieles y su relación con el espacio natural. Este panorama empeora si se considera que la fiesta se ha ido posicionando en la mira de la

23 Ceruti (2007: 18-19) resume de manera general lo que acontece en este tiempo: El núcleo de la celebración está constituido por las invocaciones al Señor de la Estrella de la Nieve, las ofrendas andinas a los apus, la adoración de la peña sagrada en la capilla, las procesiones a la gruta de la virgen, todas ellas acompañadas de las incesantes danzas de las distintas comparsas. El clímax de la festividad tiene lugar en torno a la ascensión de los ukukus al nevado y las prácticas iniciáticas de flagelación con azotes. Entre los ritos que acompañan la ceremonia se cuentan las peticiones de carácter lúdico efectuadas por medio de miniaturas o alacitas, en la terraza de los juegos, la recolección de hielo, cera y hierbas en calidad de reliquias y las prácticas adivinatorias a través de la contemplación de velas encendidas. El festejo religioso en el santuario culmina con una misa de bendición.

24 La veneración a las montañas "Apu Colquepunku” y "Mama Sinakara", deidades que existían previas a la conquista (Randall, 1982); o la concepción de la muerte como una ofrenda a los espíritus de la montaña, aplicado para las muertes accidentales que pueden ocurrir durante el ascenso de los personajes de la peregrinación denominados ukukus, al caer en las grietas del glaciar (Ibíd.).

25 Desde el año 1997 más de treinta organizaciones migrantes de cusqueños en Lima metropolitana realizan la fiesta del Señor del Qoyllur Riti con misas en quechua y la procesión de los santos. (Ávila, 2004: 7). Lo mismo ocurre con migrantes limeños en la ciudad de Nueva York. Se puede decir que "en la actualidad, el culto se ha convertido en un importante símbolo de la "cusqueñidad” en Lima y de la "peruanidad” en Estados Unidos” (Ibíd.: 2). 
industria turística y que, poco a poco, atrae a una nueva variedad de visitantes. Las instituciones locales del Estado empiezan a promocionar este y otro tipo de religiosidades de la zona andina como parte de un etnoturismo.

\section{Turismo y patrimonialización}

La visita cada vez mayor de visitantes exógenos llega a la montaña con la idea de que la peregrinación es de tradición andina y ancestral, por tanto de adoración a la tierra, no contaminada por el mundo moderno material. Muchos visitantes se chocan con una realidad que no encaja con este preconcepto etnocéntrico y folkorizado, en especial al observar las prácticas comerciales y las peticiones que se hacen al Señor del Qoyllurit'i, en la terraza de los juegos ${ }^{26}$. Se juzga esta conducta como "materialista" pues, según sus expectativas, la ceremonia debería ser más bien "espiritual" (Carreño, 2012). Estas interpretaciones son una reinvención del mito del "buen salvaje", en donde se tiene la percepción de que las llamadas "culturas tradicionales" tienen una relación armoniosa con la naturaleza y con los espíritus que en ella habitan. Se relaciona de manera esencializada lo indígena con el conservacionismo y la espiritualidad.

\section{Festividad ordenadora del cosmos}

Hablar del Qoyllurit'i como expresión propia de la cultura andina, brindando la idea de una identidad estática y homogénea es un error. La peregrinación no sólo gira en torno al fenómeno religioso, sino que para muchos migrantes el encuentro supone un ejercicio de redefinición de la cultura y de las identidades frente a contextos más globales (Ávila, Globalización y rituales religiosos andinos transnacionales. El culto al taytacha Qoyllur Ritti en Cusco, Lima y Nueva York, 2004). Es posible entender esta estrategia como una forma de organizar el mundo para sujetos rurales migrantes en las grandes ciudades. Recordemos que esta fiesta se ha trasladado hasta lugares tan distantes como Lima o Nueva York, lo que ha dado pie a la aparición de comunidades transnacionales que comparten un pasado común y pueden construir sentimientos de autovaloración y mayor confianza, como estrategia para enfrentar la discriminación y opresión a la que, muchas veces, se ven expuestos (Yelin, 2002 en: Ávila, 2004). Asimismo, la peregrinación puede ser considerada una herramienta para construir un sentido de cosmos que ordene el caos producido por la interacción entre dos mundos tan diversos en el espacio como el campo y la ciudad, o en el tiempo; como lo tradicional y el mundo moderno. Hablamos de lo que García Canclini denomina "estrategias para entrar y salir de la modernidad" (Canclini, 1992 en: Ávila, 2004: 14).

\section{Un análisis del contexto: nación, multiculturalidad y patrimonio, el caso de Ecuador, Colombia y Perú}

Catherine Walsh (2008: 134) advierte que los estados nacionales de América han basado su formación en "una pretendida homogeneidad y unidad, la cual ha permitido mantener la dominación económica, política, social y cultural y alentar los intereses del capital y del mercado". Aunque los estados sudamericanos se fundaron en estructuras monoculturales y uninacionales, cada estado nación ha enfrentado un recorrido histórico distinto y hoy comprende y se relaciona de diferentes maneras con la diversidad cultural que habita en su territorio. Indagar la relación existente entre las expresiones culturales, la normativa y la institucionalidad de cada país es una

26 En este espacio se realizan representaciones lúdicas y parodias de casamientos, transacciones comerciales y demás formas de interacción social. Son una especie de performatividad de lo que los peregrinos desean obtener durante el año. Otra forma de simbolizar estas peticiones son las "alacitas" cuyo origen son las regiones de influencia qolla y que son una especie de materialización simbólica de los objetos deseados. Se trata de figuras en miniaturas que las representan (Ceruti, 2007: 21). 
tarea amplia y compleja que no se puede abordar de manera profunda en este texto. Sin embargo, es posible obtener algunas conclusiones a partir de los documentos constitucionales vigentes en los países de estudio, Colombia, Ecuador y Perú.

Colombia se considera, según la constitución de 1991, un "estado democrático, participativo y pluralista" (art.1). Reconoce la diversidad étnica y cultural de la nación (art.7), admitiendo la existencia de una diversidad lingüística (art.10) y religiosa ${ }^{27}$. En Perú, la constitución aprobada en 1993 afirma que "El Estado reconoce y protege la pluralidad étnica y cultural de la Nación" (art.2, numeral 19) y "respeta la identidad cultural de las Comunidades Campesinas y Nativas" (art.89). Ecuador, por su parte, aprueba la constitución en 2008 y se considera un Estado laico, plurinacional e intercultural (art. 1). Los idiomas ancestrales son de uso oficial en sus respectivos territorios, el castellano es el idioma oficial y el quechua y el shuar son idiomas oficiales de comunicación intercultural (art. 2).

Esta mirada general permite notar que el reconocimiento de la diversidad cultural y el empoderamiento de otros pueblos no blanco-mestizos han tenido un desarrollo y un reconocimiento disímil en cada caso. En Perú, -uno de los países de América con mayor porcentaje de pueblos indígenas-, la Carta Magna no reconoce esta diversidad más que como un objeto a ser protegido y, en el mejor de los casos, "respetado". Colombia, por su parte, se considera un estado pluralista y reconoce la diversidad, pero este reconocimiento no implica ni interacción ni inclusión en relación con la sociedad dominante.

El caso de Ecuador difiere de los anteriores, ya que, gracias al trabajo de múltiples colectivos sociales y del movimiento indígena, se ha logrado que varios pueblos y nacionalidades puedan ser reconocidos como tales. La nación ecuatoriana se define como "plurinacional e intercultural", cuestionando así la idea de estado uninacional y el monopolio que se ha ejercido históricamente en los modos de construir la identidad, la territorialidad y la cultura misma. La plurinacionalidad implica el reconocimiento de las 14 nacionalidades y 18 pueblos que habitan en el territorio ecuatoriano $^{28}$. Los zápara constituyen una de estas nacionalidades.

El reconocimiento de la interculturalidad implica una propuesta de transformación radical de las estructuras, instituciones y relaciones de la sociedad, lo que a su vez implica "implosionar desde la diferencia en las estructuras coloniales del poder como reto, propuesta, proceso y proyecto; es hacer reconceptualizar y re-fundar estructuras que ponen en escena y en relación equitativa lógicas, prácticas y modos culturales diversos de pensar, actuar y vivir" (Walsh, 2008: 141).

Cabe anotar que las nociones básicas de patrimonialización difieren de la propuesta de interculturalidad, puesto que el patrimonio busca presentar una imagen de armonía, sincronía y coherencia, se evita evidenciar el conflicto y se espera que estas expresiones sociales se adhieran a las políticas hegemónicas como una especie de diversidad domesticada. Por el contrario, la interculturalidad, como ya se anotó, implica procesos de negociación, disputa e interrelación en relación con lo establecido ${ }^{29}$.

\section{Conclusiones e implicaciones}

Las nociones de patrimonialización y, particularmente aquellas propuestas por la UNESCO se enmarcan en el proceso de constitución y fortalecimiento de los Estados, por lo que, en muchos casos, existe una pretensión de expropiar a las expresiones inmateriales de los sentidos

27 Anteriormente, según la Constitución colombiana de 1886 el único idioma oficial era el español y la única religión la católica.

28 Según datos del Consejo de Nacionalidades y Pueblos del Ecuador (CODENPE).

29 En este sentido Walsh (2008) advierte sobre el peligro del uso indistinto de los términos "interculturalidad" y "multiculturalidad", en especial por entes como el Estado, las ONG's, y los organismos internacionales (Banco Mundial, BID, PNUD y UNESCO), haciéndolos parecer términos sinónimos, oscureciendo la historia de lucha detrás del término "intercultural", otorgándole un sentido "universal" y volviéndolo funcional al status quo. 
de lo cultural. El proceso se enmarca en la lógica de la multiculturalidad, que acepta la diversidad pero tiende a sostener los intereses de los sectores dominantes y hegemónicos; es decir, admite la diferencia para administrarla dentro del orden nacional.

En el caso de Palenque de San Basilio, es muy evidente la utilización de esta expresión para la concreción de la red de sentido nacional de Colombia, que reconoce la diversidad étnica y cultural de la nación, como estipula la constitución de 1991 (art. 7), sin que esto implique que la población afrodescendiente tenga un mayor acceso a derechos y oportunidades. A cambio de la nominación de patrimonio inmaterial de la humanidad las comunidades palenqueras reciben los "beneficios" de un marketing turístico bastante folcklorizado que no implica ningún cambio estructural en la histórica discriminación vivida por el pueblo afrocolombiano y que podría entorpecer los procesos de revitalización cultural surgidos en los años ochenta.

Se evidenció un proceso de apropiación más organizado en el caso zápara. La nominación se mostró como un instrumento útil al momento de negociar con el poder debido a la existencia de una organización comunitaria y también a causa del difícil acceso a su territorio, que limita la intervención de la industria turística. Sin embargo, existe una influencia por parte de ONG's e instituciones estatales con sus respectivas presiones políticas. A la vez, la nominación ha abierto espacios mediáticos en los que se presenta a los záparas como seres étnicos pertenecientes a una categoría especial, permitiendo perpetuar la colonialidad bajo una engañosa categoría de revitalización que no apunta a cambiar las estructuras.

También puede ocurrir que la nominación tenga connotaciones menores para una expresión cultural vigorosa, tal parecería ser el caso del Qoylluritti. Es posible que esto se deba al poco tiempo transcurrido desde la nominación (2011) o a las particularidades propias de esta expresión cultural. Sin embargo, no se puede descartar que la promoción turística generada por la nominación y las diversas instituciones involucradas, que han provocado un constante aumento de visitantes exógenos, llegue a generar una espectacularización de la realidad a mediano plazo.

En todos los casos revisados, el límite de lo patrimonializable viene impuesto desde nociones occidentales como derechos humanos, desarrollo sustentable, lo étnico, con lo cual se delimita a la diversidad cultural dentro de un marco de lo moralmente aceptable, desde una óptica etnocéntrica y eurocéntrica. Asimismo, la propuesta de lista representativa o la de obras maestras reduce la inmensa creación humana a una selección basada en criterios estéticos específicos, supuestamente imparciales, bajo los cuales se folckloriza una realidad con el fin de que esté disponible para ser direccionada, en muchos casos, hacia el fortalecimiento de una identidad nacional y de un sistema hegemónico. Quizás la intención sea dar la imagen de respeto a la diferencia, aquella multiculturalidad de la que se habló anteriormente, que le gusta mostrar lo "auténtico" y lo diverso, siempre y cuando eso no implique un cuestionamiento del estatus quo. Se patrimonializa así una otredad esencializada.

La conservación patrimonial no es acto benéfico desinteresado, sino que tiene contundentes connotaciones políticas; es capaz de ejercer una clara dominación cultural. A la vez existe la posibilidad de dotar de significados al presente y, por tanto, utilizar una nominación resignificándola para intereses de los actores sociales. A manera de cierre se debe enfatizar la importancia de conocer las particularidades de cada caso, para ir más allá de una crítica general a los procesos de patrimonialización, completando esta mirada con el conocimiento de lo particular. En este sentido, la academia tiene una deuda pendiente, pues ha actuado como diseñadora del discurso patrimonial, como crítica del mismo, como mediadora entre los productores culturales y los funcionarios estatales. Entre todos estos papeles existe aún la deuda de un acercamiento a las experiencias concretas de las expresiones sociales que viven ahora con una nominación de "patrimonio inmaterial de la humanidad".

Es, sin duda, la antropología, una de las ciencias llamadas a asumir este compromiso para entender y evaluar las consecuencias y las implicaciones de la patrimonialización. No basta con una recopilación de datos observables, hace falta conocer cómo interioriza la gente el 
proceso, intentando entender el discurso de los actores y hacer evidente si conlleva actitudes y prácticas de resistencia, resignificación, negación o reproducción del sistema. Se requiere evidenciar los conflictos, las dudas, los engaños, los beneficios y las estrategias propias de los procesos. Procuremos que la construcción del patrimonio cultural no se convierta finalmente en un ejercicio de uniformidad y represión. Así, se formula una invitación a plantear más cuestionamientos y trabajar desde la certeza de que se puede construir no sólo desde arriba, sino desde otros espacios alternos, desafiando el marco hegemónico desde el cual se cuenta la historia. Se requiere participar desde la academia, pero también desde la vida diaria para releer, reimaginar y reinventar. 


\section{Bibliografía}

Ariño, A. 2009, "La patrimonialización de la cultura y sus paradojas”, en: Gatti Casal del Rey, Gabriel et al. (Coords.) Tecnología, cultura experta e identidad en la sociedad del conocimiento, Universidad del País Vasco, España, pp 131-156.

Andrade, C. 2001, Kwatupama Sapara, Palabra Zápara, Abya Yala, Quito-Ecuador.

Ávila, J. 2004, "Globalización y rituales religiosos andinos transnacionales. El culto al taytacha Qoyllur Ritti en Cusco, Lima y Nueva York", en: Gazeta de Antropología, 20 en: http://hdl.handle.net/10481/7262

Asamblea Nacional. 1998, Constitución del Ecuador. Quito, Ecuador.

Bilhaut, A. G. 2011, El sueño de los Zaparas: Patrimonio onírico de un pueblo de la alta Amazonia, FLACSO -Abya Yala, Quito.

Beck, U. 1998, ¿Qué es la globalización? Falacias del globalismo, respuestas a la globalización, Paidós, Barcelona.

Bellido, M. E. 2012, Qoylluriti, una peregrinación que mueve montañas, Ministerio de Cultura, Perú.

Canclini, N. 1999, "El consumo cultural: una propuesta teórica", en: Sunkel Guillermo (Coord.) El Consumo Cultural en América Latina: construcción teórica y líneas de investigación, $2^{\circ}$ edición, Convenio Andrés Bello, Bogotá, pp. $72-95$.

Chaves, M. et al. 2010, "Mercado, Consumo y Patrimonializaciòn Cultural”, en: Revista Colombiana de Antropología , 46, pp. 7-26.

Ceruti, M. 2007, "Qoyllur Riti: etnografía de un peregrinaje ritual de raíz incaica por las altas montañas del Sur de Perú", en: Scripta Ethnologica, XXIX, pp. 9-35.

Carreño, G. S. 2012, "Curanderos, peregrinos y turistas. Procesos interculturales en la sociedad cusqueña contemporánea”, en: Anthropologica, 21, pp. 145-171.

Constitución de la República de Colombia, 1991.

Constitución política de Ecuador, 2008.

Constituciòn Política de Perú, 1993.

El Telégrafo. 26 julio de 2017, "Con muerte de Cesario Santi solo quedan cuatro precursores de la lengua zápara en Ecuador”, recuperado de http://www.eltelegrafo.com.ec/noticias/sociedad/4/murio-cesario-santi-y-solo-quedancuatro-precursores-de-la-lengua-zapara-en-el-ecuador

Estraffi, E. 2014, Los mayas de hoy y los sitios arqueológicos, interpretaciones y actividades rituales, Abya Yala, Quito, Ecuador.

Guerrero, P. 2004, Usurpación simbólica, identidad y poder. La fiesta como escenario de lucha de sentidos, Universidad Andina Simón Bolívar, Sede Ecuador; Corporación Editora Nacional; Ediciones Abya Yala, Quito, Ecuador.

Hall, S. 2005, "Whos heritage? Un-settling 'The heritage', re-imagining the post-nation". The politics of heritage: The legacies of 'race. ', 21-31.

Márquez, M. 2003, Una reflexión sobre el Patrimonio Oral e Intangible: El Pueblo Zápara, Universidad Andina Simón Bolívar, Quito, Ecuador.

Mignolo, W. D. 2003, Historias locales, diseños globales: colonialidad, conocimientos subalternos y pensamiento fronterizo, Akal, Madrid, España.

Moya, A. 2007, Sápara: los aritiakus, hijos e hijas del mono colorado, UNESCO.

Observatorio de Patrimonio Material. 2009, Estudio de caso: percepciones sobre el proceso de declaratoria de Palenque de San Basilio, COLCIENCIAS, Fundación Erlgale y el Instituto Colombiano de Antropología e historia.

Prats, L. 1997, Antropología y patrimonio. 20.

Presidencia de la República de Colombia, Ministerio de Cultura, Instituto Colombiano de Antropología e Historia. 2002, Palenque de San Basilio, Obra maestra del Patrimonio Intangible de la Humanidad” Bogotá D.C., Colo. Dossier de Candidatura, Bogotá.

Randall, R. 1982, "Qoyllur Riti: An Inca Fiesta of the Pleiades. Reflections on Time and Space in the Andean World", en: Bulletin de l'Institut Français d'études andines, 11, pp. 37-81.

Rendón J.G. 2014, "De-construir el patrimonio", en: Rostein, Stephen (Ed.) Antes de Orellana, Actas del 3er Encuentro Internacional de Arqueología Amazónica, Quito, pp. 423-431.

Rendón, F. 2014, "Bonga, el caso de la activación patrimonial de San Basilio de Palenque y el desplazamiento forzado de sus campesinos a causa del terror en Montes de María”, Tesis de grado, Universidad de Antioquia, Facultad de ciencias sociales y humanas, departamento de antropología, Medellín, Colombia.

Restrepo, E., y Pérez, J. N. 2005, "San Basilio de Palenque: Caracterizaciones y riesgos del Patrimonio intangible”, en: Revista de Antropología Jangwa Pana, Universidad de Magdalena, Santa Marta, Colombia, pp. 58-69.

Salge, F. M. 2012, "El patrimonio cultural inmaterial en San Basilio de Palenque, en busca de las representaciones de lo palenquero a través de la prensa nacional", en: Memorias. Revista digital de Historia y Arqueología desde el Caribe colombiano. 
Santoyo, A. A. 2006, "Informe del proyecto: Investigación para la definición de un marco conceptual de la política sobre patrimonio cultural inmaterial en Colombia", Observatorio de Patrimonio Material, Inmaterial y Arqueológico (MIA) Instituto Colombiano de Antropología e Historia -ICANH, Bogotá, Colombia.

Unesco. 2010, Expediente de aplicación, La peregrinación al santuario del Señor de Qoyllurit'i.

2003, Convención para la Salvaguarda del Patrimonio Inmaterial, París.

1972, Convención para la Protección del Patrimonio Mundial Cultural y Natural, París.

1945, Constitución de la Organización de las Naciones Unidas para la Educación, la Ciencia y la Cultura, Londres.

Velasco, H. 2012, "De patrimonios culturales y sus categorías", Gazeta de Antropología, 28, en: http://www. gazeta-antropologia.es/wp-content/uploads/GA-28-3-13-HonorioVelasco1.pdf.

Villaseñor, I., \& Zolla, E. 2012, "Del patrimonio cultural inmaterial o la patrimonialización de la cultura", en : Cultura y representaciones sociales, año 6, $\mathrm{N}^{\circ} 12$, pp. 75-101. http://www.culturayrs.org.mx/revista/num12/ VillasenyorZolla_12.pdf

Walsh, C. 2008, Interculturalidad, plurinacionalidad y decolonialidad: las insurgencias político-epistémicas de refundar el Estado. Tabula Rasa, № 9, Colombia, pp. 131-15. http://www.scielo.org.co/pdf/tara/n9/n9a09.pdf 